\title{
Study on the Stratified and Sub-curriculum-oriented Teaching Model*
}

\author{
Qin Li \\ Jiangxi Institute of Fashion Technology \\ Nanchang, China
}

\begin{abstract}
The paper introduces the model of the stratified and sub-curriculum-oriented college foreign languages teaching model applied in Jiangxi Institute of Fashion Technology, provides its theoretical basis, discusses its practices based on the survey among students, hoping to contribute to the improvement of the college foreign languages teaching.
\end{abstract}

Keywords-college students; stratified teaching; subcurriculum-oriented teaching; teaching model

\section{INTRODUCTION}

\section{A. The Background of the Study}

1) Students' real situation: Coming from all over the country, college students are characterized by different foreign languages proficiency upon their enrollment, different learning needs and different interests. Most students have undergone 9 years' experience of English learning during their middle school, each scoring differently in the college entrance examination. In addition, students of arts and science are obviously different in the college entrance examination pass rates. Some come out with credit, some are at the level of passing, others failed, and still others only have enrollment 30 points. Moreover, most students have imbalanced development in listening, speaking, reading, writing and translating, a little bit better in reading, less satisfactory in listening, and far less unqualified in speaking or writing. How can the college students meet the requirements stipulated in the teaching program? Students come from different teaching quality areas, with different foundations, capacities, and English proficiency. Traditional teaching shares the same objectives and teaching materials, thus seriously hampering their interest and hindering their improvement. In order to solve the problems of college students' low efficiency and low interest in English learning, Jiangxi Institute of Fashion Technology carried out the multilingual teaching reform based on the sub-curriculum-oriented and stratified teaching model.

*Fund: This paper was the research results of Jiangxi provincia project "The Exploration of College Foreign Languages Teaching Based on the stratified and Sub-curriculum-oriented Teaching Model" in 2017 ((No.: JXJG-17-26-11)
According to statistics, this institution had 1869 new college students' enrollments in 2017, with 967 scoring less than 60 , accounting for $51.7 \%$, and with 398 scoring more than 90 points, taking up $21.1 \%$, the number of students whose scores fall in between 90 points and 60 points is about 504 , occupying $26.9 \%$. The following bar chart can illustrate the gloomy situation.

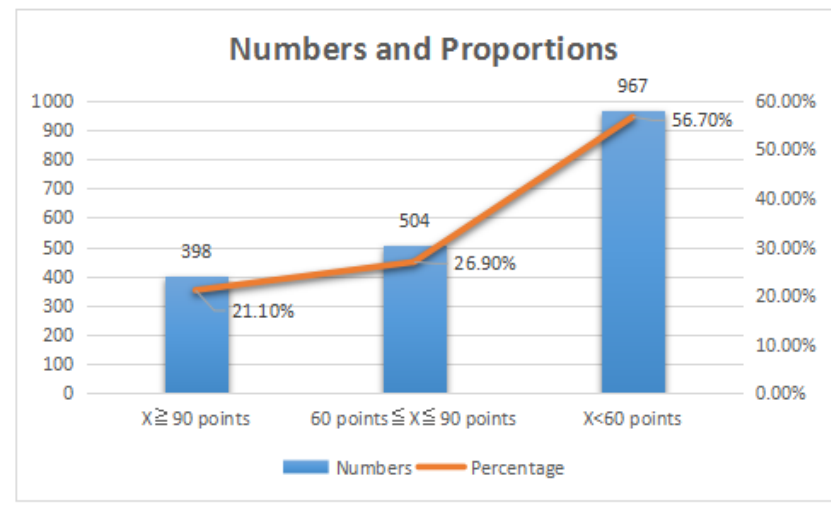

Fig. 1. Numbers and Proportions of Students with different English Enrollment Scores.

2) The new-established language competence standard: China's first scale for English proficiency levels will be implemented June 1 this year. The scale, which is divided into nine levels based on English proficiency, covering all the education periods from elementary school to university, will be helpful and facilitating in unifying various English tests with different standards and deepening the interconnection between exams at home and abroad. Along with defining competencies in listening, speaking, reading and writing, the scale also includes pragmatic competence, such as translation and interpretation. This aims to help foster students' practical language capacity, cultural awareness and intercultural communication skills. The scale also attaches great significance to the cognitive development of language learning so as to better cultivate students' thinking abilities. Students should be aware that the inevitable future international and intercultural communication is a greater challenge to them. 


\section{B. The Necessity of Stratified and Sub-curriculum-oriented Teaching}

The challenge of balancing different levels is increasingly becoming an obstacle in both teaching and studying. Taking stratified and sub-curriculum-oriented teaching model can be a good option for teachers to solve the problem.

In order to satisfy needs from different levels of students, stratified and sub-curriculum-oriented teaching model was adopted and implemented. After layering, the same or similar level of students possessing the similar basis, study together in the same class, learn and progress at the same rate. Following the others easily allow the students to be more confident to learn without giving up. Meanwhile, the stratified and sub-curriculum-oriented teaching model makes the teaching a project with a firm purpose and strong pertinence. Instead of spending more time and energy on different levels, teachers can focus on the lesson for one level student.

\section{STRATIFIED AND SUB-CURRICULUM-ORIENTED TEACHING MODEL'S CONSTRUCTION}

\section{A. Theory Basis}

The re-knowable educator and great thinker in ancient China, Confucius, advocated that teaching should be based on their different aptitudes. Ever since it was put forward, it has been regarded as one important method and principle in the teaching course. Each individual varies from others in the aspects of quality, the cognitive levels, learning ability. While teaching, their different study habits, foundation, interests and capacities are by no means should be taken into consideration. In order to enhance student' strengths, arouse their interests, build their confidence and boost their allround development the teacher chooses varied teaching methods for every student to suiting the instruction to students' level.

In his 1983 book Frames of Mind, the author Howard Gardner proposed the concept of multiple intelligences. Theoretically, there exist eight different intelligences namely musical-rhythmic, visual-spatial, verbal-linguistic, logicalmathematical, bodily-kinesthetic, interpersonal, intrapersonal, and naturalistic. In Gardner's view, intelligence is "a biopsychological potential to process information that can be activated in a cultural setting to solve problems or create products that are of value in a culture." [1] The criterion of single general ability is too narrow to be applied to define a person. Under the influences of the traditional education system's enormous focuses on intelligence quotient, verballinguistic ability and scores, teachers always share different students the same materials by the same method and dealt with students as one individual. Actually, individuals do differ in the above eight intelligences. We can achieve our goals to invoke and combine students' different and strong intelligences by implementing different tasks, solving diverse problems, and learning properly.

Based on the students' existing knowledge, ability levels and potential tendency, stratified teaching enables the teacher to divide the students into several groups at similar levels and treat levels in different ways. Different teaching methods and strategies are supposed to be employed according to the real class teaching situations. The stratified teaching is to recognize, consider and apply students' difference in intelligences, aptitudes as well as at foreign languages levels, and try to teach them by their strong aptitudes and intelligences.

Krashen points out that the basis of language acquisition is language input. In order to learn a language, learners need to get a lot of modified and comprehensible input. On the basis of the input hypothesis [2], Swain puts forward the output hypothesis[3], emphasizing that output can encourage learners to pay attention to the language form, test the students' assumptions about the target language, and analyze and reflect the language forms according to the feedback. He also emphasized the effect of output on the application of language. According to his theory, the domestic researcher Wen Qiufang further proposed the "output driven hypothesis"[4], which consists of three sub- hypotheses: output has greater driving effect on improving foreign language ability than input; without output, the high quality of input can only gain limited effect; application of the language is the most essential in learning English. Viewing from the social needs for language skills, compared with listening and reading (the two receptive skills), speaking, writing and translating (the three expressive skills) are more important, especially in oral and written translation. From the perspective of foreign languages teaching, the output oriented integrated teaching method can achieve greater effectiveness than the single skill training method [5].

Inspired by the above mentioned theories, we think subsub-curriculum-oriented teaching model can also solve our difficulties in language teaching. Level-A students can take the form of comprehensive teaching; Level-B students should give priority to their improvements in the aspects of reading and writing; Level-C students need to spark the learning interest by taking one receptive skill (listening) and one practical, expressive skill (speaking).

The stratified and sub-curriculum-oriented teaching combined into one integrity and then involves multi foreign languages teaching, resulting in the existing foreign languages teaching model in Jiangxi Institute of Fashion Technology, which has been practiced for more than half year, yielding some achievements.

\section{B. Stratified and Sub-curriculum-oriented Teaching's Model}

Based on the students' different foundations, levels, interests and requirements, stratified teaching centers focus on the students' needs, willingness and capabilities. Retrospection some students' painstaking experience of English learning, the college should have to consider carefully whether the students need to learn English course or not. The purpose of learning a foreign language is to communicate naturally and fluently in the wide world and facilitate people's future life and job. Besides English, many other languages can also be good options for non-English 
majors to select. At the students' requests, our college offers Korean and Japanese courses at present.

The teaching model is an open, dynamic framework of teaching activities and procedures under the guidance of certain teaching theories, connecting teaching theories with the real teaching practice. Not only being the application of teaching theory, but also a direct guide to teaching practice, the teaching model lead and guide the whole process of teaching, examination. Based on the teaching purposes and theories, students' characteristics and requirements as well as combination of the real teaching conditions, the faculty has formed the following teaching model:

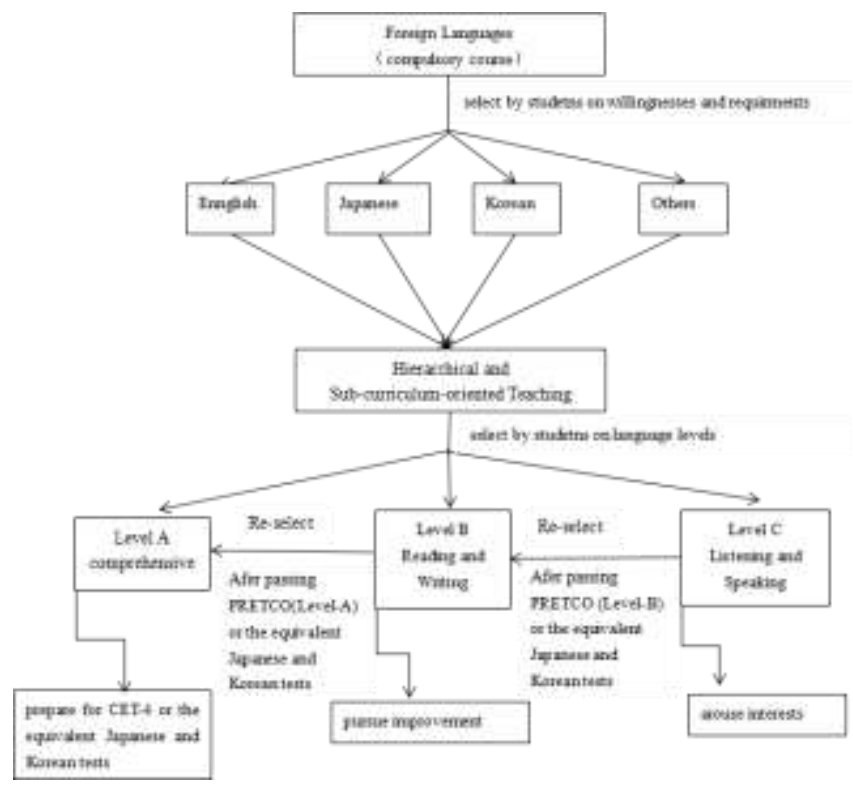

Fig. 2. Stratified and sub-curriculum-oriented teaching model.

This teaching model, with many languages offered, tries to improve the teaching effectiveness. Students can select one of the languages according to their real interests, future needs and English scores in the college entrance examination. There are three levels in each language, namely Level A, B and $\mathrm{C}$ relatively. The highest level is Level $\mathrm{A}$ which is offered for the students who have better command of the language. Level $\mathrm{B}$ is lower than level $\mathrm{A}$ and level $\mathrm{C}$ is the lowest. Despite the existence of the three levels, it doesn't necessarily mean the students in level $\mathrm{C}$ class are the poorest performer. It just indicates that these students' English foundations are not as good as others and both the teachers and students need to make joint efforts to reinforce their foundations, stimulate their interests in language learning. Never can teachers divide students into bad ones and good ones by levels. As a matter of fact, different levels just provided a certain scale for teachers make concrete targets, use proper methods and organize appropriate activities for each level.

Nothing is perfect. This model will be no exception in the real teaching practice.

\section{STRATIFIED AND SUB-CURRICULUM-ORIENTED TEACHING MODEL}

\section{A. Determining Teaching Objectives}

CET-4, whose importance has always been highlighted in college English teaching, remains vital to employment for most college students. Conducting CET-4 special and comprehensive training is necessary to make the outperformers pass CET-4. To encourage and improve the complete losers' (those with the enrollment scores less than 30) self-confidence and interest in language learning, it is necessary to offer alternative options except for studying English. The institute tries to give the unsuccessful examinees in college entrance examination alternative options, namely English, Japanese and Korean. If they choose to study English, the institute wills properly training them in Basic English listening and speaking to handle the simple daily general communications. For those who are at the medium level, preparing for PRETCO is an imperative for the college English teaching. The medium level examinees should focus on English listening, writing and translating, which will lay down a foundation for their future exploration into English.

Students who select to study Japanese and Korean also share the equivalent objects.

\section{B. Determining Selecting System and Methods}

The institute Academic Affairs Office System meets all the requirements of selecting courses. The foreign language course is a compulsory course which will be open for one year for the college students. With the help of the system, all the foreign language courses are arranged ahead of other courses in the timetable, which can ensure that all the students attend the courses at the same time and students at the same level can learn in the same class.

Students can either select the different courses on the internet ahead of time or actually come into the classroom to listen to the class and make their names listed on the teacher's name-sheets.

\section{Teaching Practice}

To understand the actual English proficiency and learning needs and demands of our college students, a questionnaire survey was conducted among the students enrolled in 2017. 313 were more willing to enhance their listening and speaking, and 235 asked for CET-4 past exam paper related text books or expanded textbooks, accounting for $12.5 \%$. The survey results also told us only $21.2 \%$ were satisfied with traditional English teaching, 53.9\% felt average. Among the whole students, $78.8 \%, 70.9 \%$ and $32.7 \%$ respectively welcomed better performance in listening, reading and speaking. $82.3 \%$ regarded listening as the biggest obstacle and difficulty. When it comes to the teaching content, most unsuccessful examinees in the college entrance examination valued PRETCO exam paper and the relative expanded content, while most of the successful examinees were looking forward to improve listening and speaking, or listening, speaking, reading, writing and 
translating simultaneously, indicating great differences in capacity, demands and needs. The faculty interestingly found students who wanted to select other foreign languages also, was eager to pass PRETCO and CET-4. For too many students, CET-4 was beyond their imagination. Based on "meeting and serving the students' needs first", we tentatively conducted the stratified and sub-curriculumoriented teaching research and teaching practice to meet different needs of students with different English proficiency.

1) Levels of students and teaching objectives: College students enrolled in 2017 were divided into 3 levels, namely A, B and C, according to their College Entrance Examination results and their willingness. Level A referring to the successful examinees, took English test and comprehensive application capacity, CET-4 as the main objectives, making them competent in the general English exchange in future work and social interactions. Level B and Level $\mathrm{C}$, which refer to unsuccessful examinees in the college entrance examination, adopted sub-curriculumoriented teaching, focusing on the main aim of boosting the development of two skills (Level B focusing on reading and writing; the Level $\mathrm{C}$ aiming at cultivating learning interest and developing the basic listening and speaking). Students at level $\mathrm{C}$ can re-select the course after they pass PRETCO (Level-B): the students have the right to apply for Level B from Level $\mathrm{C}$ in the second semester. Students at level B can re-select the course after they pass PRETCO (Level-A): the students have the right to apply for Level A from Level $\mathrm{B}$ in the second semester. So the teaching system is open and dynamic.

Students who select to study Japanese and Korean also share the equivalent objects and demands.

2) Different teaching content:Level A students selected the national programmed teaching material and the real CET-4 exam papers. Intensive reading focused on CET-4 special and comprehensive training, especially listening.

Students on Level B took a specialized reading and writing material and the PRETCO (Level-A) real exam papers as the supplemtary material.

Level C students employed a specialized listening and speaking material, which suited their capacity and proficiency. Also PRETCO (Level-B) real exam papers are applied as a helpful material.

3) Varied teaching method: To achieve Level A teaching objectives, the faculty put students first, taking multiple teaching methods, such as discussion teaching method, comparison method, interactive teaching method, flipping teaching, task teaching method, modern multimedia teaching method, and interactive teaching method, creating the harmonious classroom atmosphere, organizing brainstorming, developing divergent and critical thinking ability. The teaching focused on listening, reading, writing and translating, explanation and training, comprehensive training, comprehensive simulation, and comprehensive test, striving to prepare them for CET-4.
Level B students focused on reading and writing, explanation and training, comprehensive training, comprehensive simulation, and comprehensive test, striving to improve their PRETCO (Level-A) pass rate.

Level $\mathrm{C}$ teaching attach great importance to reading and writing, explanation and training, comprehensive training, comprehensive simulation, and comprehensive test, striving to improve their PRETCO (Level-B) pass rate. Most students took listening as the biggest obstacle, challenging and centering on dialogues, texts, and dictations, and constant training.

Translating checked students' grammar foundation and knowledge, such as: virtual tone, sentence structure, subjectpredicate consistency, and non-predicate as adverbial etc. Writing teaching required some time-consuming and painstaking tasks such as idea explanations, language and passage organization, some beautiful, standard sentences and even paragraphs memory. Fast reading, being a way enlarge vocabulary and enforce linguistic rules, required fast completion and explanation against the answer and solutions. The faculty had to teach the required basic skills and ask students to get familiar with relevant test essential, strengthening vocabulary training so as to improve their listening, speaking, reading and writing.

4) Alter the traditional teaching evaluation :Students of various levels should be assessed to obtain the accurate and effective teaching feedback. The papers serving different levels should be fair and rational and in line with their different teaching objectives and requirements. The faculty should assess Level A students through their attendance, oral presentation, audition, homework (translation, short essays), normal results and final results. Level-B class students took closed-book exams and final assessment, taking PRETCO (Level-A) as standards, including reading (comprehensive reading, fast reading, true of false judgement, cloze), translating and writing etc. Level-C class students took closed-book exams and final assessment, taking PRETCO (Level-B) as standards, including listening reading (shout and long conversations, cloze, true of false judgement, dictation), and translating etc.

5) Students' Satisfaction Survey: By January 2018, the stratified and sub-curriculum-oriented teaching model had been carried out for a semester, the foreign language faculty conducted a questionnaire survey on students' satisfaction with their studies. The survey covers 6 level-A classes, 6 level-B classes and 6 Level-C class.

The Questionnaire was conducted in January 2018 among students in terms of "Improvement in English", "Your Ideal Curriculum". "Switch Your Level-Class Or Not" and "Teaching Model Appraisement", with 80\% students giving their thumbs up, indicating that most students, especially for level-A and B students, are satisfied with the existing teaching model and show great concern for learning. Minority level-C students are not so much interested and they do less well in learning and some students are worrying that teachers and other students will look down upon lowergrade students. About $45 \%$ students expressed their 
improvements in reading, writing, listening or comprehensive skills. Almost all students say they will not switch into another class and if they make their efforts they can keep up with the teacher.

Seven foreign language teachers were also interviewed to get more feedback. One of them teaches level-A class, two of them teach level-B classes and the other two teachers are in charge of level-C classes, the rest two teachers engaging in Japanese and Korean teaching. The main interviewed questions are: 1. how do you appraise students' attendance? 2. How do students behave in class? 3. How many difficulties do you come across when preparing for the different level-classes? Most teachers expressed their satisfaction with the students' attendance and they also indicated almost all students in level-A and B classes and some of level-C students behave more actively and attentively; however, some level-C students didn't care much about the language learning.

\section{REFLECTION}

The stratified and sub-curriculum-oriented teaching model has been carried out for one semester and there is a long way to go for its improvement. In this practice, there are some deficiencies which we can take into consideration and come up with the following inspirations:

- Learn more teaching theories and further understand the stratified and sub-curriculum-oriented teaching. The stratified and sub-curriculum-oriented teaching has been explored and implemented in the primary and high schools for many years, having accumulated rich experience. However, the combination of stratified and sub-curriculum-oriented teaching model applied in multi foreign languages teaching in colleges is extremely rare. Lack of much referential experience, reading more books and comprehending more theses on stratified and sub-curriculum-oriented teaching is a must.

- Find a more practical, efficient and all-direction ways to introduce the courses and levels. In this practice, teachers just read and explained the courses and levels by verbal words in the classroom, which required the students' all attendance. Generally, these explanations finished in several minutes, are beyond their understanding. In order to avoid the appearance of similar problems, the faculty will employ multimedia technology to accomplish the introductions of stratified and sub-curriculumoriented teaching model.

- Alter the traditional evaluation. How to organize the test and how to test the students' true abilities are real challenges. A little bit reform has arisen. Besides the exam paper, we also emphasize students' attendance, behavior on class and foreign languages' competition. Each section has a certain score. Higher scores in this kind of exam depend on students' more enthusiasm, involvement in class activities and active entry for other competitions. For example, student WanYan comes from Level-A class, won the First Prize in 2017 Global Yutong Millions of College Students Listening \& Speaking Contest with 532, 763 Competitors -- National Online L \& S Final Contest[Vocational Practical English Group (Freshmen) ]. This is the first time that our college students have obtained a national award. We should design a comprehensive evaluation system for different level students, conducting comprehensive and diagnostic evaluations, evaluating and confirming their interest, attitude, participation, and language development, recognizing their strengths and weaknesses, and assisting the faculty in improving teaching effectiveness.

After another semester, we will finish the one round teaching reform. At that time we will conduct an all-round and full coverage questionnaire survey.

\section{CONCLUSION}

The purpose of stratified and sub-curriculum-oriented teaching practice in our college is to construct a practical, effective and all participants involved teaching model, stir up students' interest in learning foreign languages and at the same time improve the faculty's teaching quality. Though the combination of stratified and sub-curriculum-oriented teaching model applied in multi foreign languages teaching in colleges is extremely infrequent, I hope this can serve as a kind of teaching reference for teachers.

\section{REFERENCES}

[1] Gardner, Howard, Intelligence Reframed: Multiple Intelligences for the 21st Century, Basic Books, 1999, P33-34

[2] Krashen,S.D The Input Hypothesis: Issues and Implications 1985

[3] Swain,M.Communication competence:Some roles of comprehensible input and comprehensible output in its development [A].In S.Gass,S.\& Madden,C.(eds.).Input in Second Language Acquisition [C].Rowley, MA: Newbury House 1985.

[4] Qiufang Wen, Output Driven Hypothesis and English Professional Skills Curriculum Reform [J]. Foreign language circles, 2008, (2): 2 9.

[5] Yi Li, Motivation Analysis of Output driven Classroom teaching model: Science and Technology Economy Market [J] 2014,12:151152 . 